\title{
Characteristics of Liver Abscess in Department of Infectious Diseases at Fann Teaching University Hospital in Dakar, Senegal
}

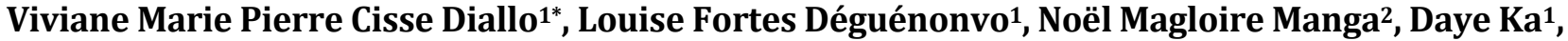 \\ Sylvie Audrey Diop ${ }^{3}$, Abdoulaye Seck4 ${ }^{4}$ Ndèye Aissatou Lakhe1, Khardiata Diallo Mbaye1, \\ Assane Diouf ${ }^{1}$, Ndèye Méry Dia Badiane ${ }^{5}$, Ndèye Fatou Ngom Guèye ${ }^{1}$, Cheikh Tacko Diop ${ }^{6}$, \\ Masserigne Soumaré ${ }^{1}$, Cheikh Tidiane Ndour ${ }^{1}$, Moussa Seydi ${ }^{1}$
}

\author{
${ }^{1}$ Infectious and Tropical Diseases Department, Fann Teaching University Hospital, Dakar, Senegal \\ ${ }^{2}$ Department of Health, Ziguinchor University, Ziguinchor, Senegal \\ ${ }^{3}$ Department of Health, Thies University, Thies, Senegal \\ ${ }^{4}$ Pasteur Institute Dakar, Dakar, Senegal \\ ${ }^{5}$ Department of Health, Gaston Berger University, Saint Louis, Senegal \\ ${ }^{6}$ Fann Teaching University Hospital in Dakar, Dakar, Senegal \\ Email: *vivich6@gmail.com
}

How to cite this paper: Diallo, V.M.P.C., Déguénonvo, L.F., Manga, N.M., Ka, D., Diop, S.A., Seck, A., Lakhe, N.A., Mbaye, K.D., Diouf, A., Badiane, N.M.D., Guèye, N.F.N., Diop, C.T., Soumaré, M., Ndour, C.T. and Seydi, M. (2018) Characteristics of Liver Abscess in Department of Infectious Diseases at Fann Teaching University Hospital in Dakar, Senegal. Advances in Infectious Diseases, 8, 23-31.

https://doi.org/10.4236/aid.2018.81004

Received: February 21, 2018

Accepted: March 18, 2018

Published: March 21, 2018

Copyright $\odot 2018$ by authors and Scientific Research Publishing Inc. This work is licensed under the Creative Commons Attribution International License (CC BY 4.0).

http://creativecommons.org/licenses/by/4.0/

\begin{abstract}
Introduction: Abscesses of the liver are due to an infection of bacterial, parasitic or fungal origin. Through amoebiological imaging and serology, their diagnosis was facilitated. The aim of this study was to determine the epidemiological, clinical, diagnostic and evolutionary aspects of these liver abscesses at the Department of Infectious and Tropical Diseases in Fann Teaching University Hospital. Patients and Methods: This was a retrospective and descriptive study, based on records of patients hospitalized for abscess of the liver over a period of 8 years, from January 1, 2008 to December 31, 2015. Results: We collected 20 cases of abscesses including 12 cases of confirmed amoebic abscesses and 5 cases of pyogenic abscesses. The mean age of the patients was $43.15 \pm 15.12$ years. There were 18 men and 2 women. The average hospital stay was 32 days. The most common clinical signs were abdominal pain $(100 \%)$, fever (75\%), hepatomegaly (80\%). A leukocytosis greater than 12,000 $\mathrm{Gb} / \mathrm{mm}^{3}$ was found in 13 patients. The amoebic serology was positive in $71 \%$ of cases and negative in $29 \%$ of cases. No germ was isolated from the blood culture. On hepatic ultrasound the abscess was unique in $90 \%$. Treatment was exclusively medical in 11 patients (55\%). The trend was favorable in $85 \%$ of cases. Conclusion: The incidence of liver abscesses has significantly decreased. It is important to develop diagnostic tools better in the case of pyogenic abscesses.
\end{abstract}




\section{Keywords}

Amoebic Liver Abscess, Pyogenic Abscess, Dakar, Senegal

\section{Introduction}

Liver abscesses are suppurations collected in a newly formed cavity within the hepatic parenchyma due to bacterial, parasitic or fungal infections [1].

Their diagnosis has been facilitated by the progress made over the last decade through the popularization of non-invasive tests such as ultrasounds. Nevertheless, confirmation of the etiology remains difficult due to the limited access to the necessary biological explorations. However, most studies in Africa are on amoebic liver abscesses [2] [3] [4]. Improving the living conditions of populations living in endemic areas, particularly increasing access to drinking water and fighting against fecal peril diseases should lead to a decline in the prevalence of this condition.

More rarely diagnosed in tropical areas, pyogenic abscesses are more common in Europe [5] where their prevalence is between 0.008 and $0.16 \%$ in hospitalized patients [6]. This incidence has likely increased according to recent studies [1] [7]. Gram-negative bacilli and anaerobic bacteria are the main culprits in 40 to $60 \%$ of cases [7] [8].

Given the improved access to diagnostic and therapeutic means in Dakar, and the lack of recent work devoted to this disease, we found it useful to carry out this work which aimed to determine the epidemiological, clinical, diagnostic and evolutionary aspects of these liver abscesses at the Infectious and Tropical Diseases Clinic in Fann Teaching Hospital in Dakar, Senegal.

\section{Patients and Methods}

This study was conducted at the Infectious and Tropical Diseases clinic in Fann teaching hospital in Dakar, Senegal, which is a public health, consultation and hospitalization service. This is the national reference center for the management of Infectious and Tropical Diseases

It was a retrospective and descriptive study based on records of patients hospitalized at the Infectious Diseases Unit for liver abscess over an 8-year period, from January 1, 2008 to December 31, 2015.

All cases of liver abscesses confirmed during the study period by abdominal ultrasound or CT scan showing an abscessed collection in the liver were included in this study. Patients who had tumor-like hepatic masses with high alpha-fetoprotein or confirmed by histology were not included.

The amoebic etiology was selected in cases of positive serology at a rate of $\geq 1 / 160$ IU through indirect immunofluorescence, or $\geq 1 / 320$ IU through hemagglutination, and/or an odorless chocolate-colored pus, which was sterile when cultured or contained amoebae, obtained using an echo-guided puncture or sur- 
gical drainage.

The pyogenic etiology was selected when the puncture revealed pus and polynuclear are altered with or without germ isolation, and/or a negative amoebic serology. This etiology was also selected in cases of a positive blood culture.

Data was obtained from the medical records of hospitalized patients. We also used data from Pasteur Institute laboratories in Dakar for amoebic serology.

A standardized data collection form was developed. It included epidemiological aspects (year of occurrence, age, sex, lifestyle, site of occurrence), clinical aspects (time of hospitalization, clinical signs), paraclinical aspects (biological signs: hemogram, VS, disruption, amoebic serology results; ultrasound signs), therapeutic aspects (medical: type, dose, duration; instrumental; surgical: indication, gesture used) and evolutionary aspects (healing, complication or death). These data was then entered and analyzed on the software Epi-Info 3.7.1.

\section{Results}

\subsection{Epidemiological Aspects}

During our study period (2008-2015), we recorded 20 cases of liver abscess among 8338 hospitalized patients, and therefore a prevalence of $0.24 \%$. The number of cases of liver abscess was higher between 2008 and 2011 (17 cases) (Table 1 ). The mean age of the patients was 43.15 years \pm 15.12 years, with extremes of 19 years and 87 years. There were 18 men and 2 women, among whom seven patients consumed alcohol, two patients had type II diabetes, and one patient was living with HIV. Traces of dysenteric syndrome were noted in five patients.

\subsection{Clinical and Paraclinical Aspects}

Patients were hospitalized within 32 days, with extremes of 3 and 180 days. Half of the patients were hospitalized within the first 20 days. Abdominal pain was reported by all patients (100\%), located in the right upper quadrant in 14 patients and was generalized to the whole abdomen in four patients. 15 patients had a fever, and 16 patients had a clinically detectable hepatomegaly (Table 2).

Biologically, the hemogram showed predominantly neutrophilic hyperleucocytosis greater than $12,000 \mathrm{~Gb} / \mathrm{mm}^{3}$ in 13 patients, and anemia in 14 patients. The sedimentation rate was accelerated in all patients who underwent this exam. Amoebic serology was positive in 12 out of 17 patients (71\%); it was not performed on 3 patients (Table 2). The rate was between $1 / 160$ and 1/640 in 2 patients $(11.74 \%)$, between $1 / 640$ and $1 / 2560$ in 3 patients $(17.64 \%)$ and greater than $1 / 2560$ in 7 patients (41.17\%).

The chest X-ray showed right-sided pleural effusion in 10 patients, pneumonia in 3 patients, and an elevated hemidiaphragm in 3 patients. According to the ultrasound data, the abscess was unique in 18 cases (90\%) and multiple in two cases (10\%). The right lobe was the preferred seat of these liver abscesses (95\%). The abscess size was greater than $10 \mathrm{~cm}$ in 7 patients. 
Table 1. Distribution of cases of liver abscess according to years of diagnosis hospitalized at the service of infectious diseases of Fann in Dakar from 2008 to 2015.

\begin{tabular}{ccc}
\hline Year & Number & Percentage (\%) \\
\hline 2008 & 2 & 10 \\
2009 & 6 & 30 \\
2010 & 4 & 20 \\
2011 & 5 & 25 \\
2012 & 1 & 5 \\
2013 & 0 & 0 \\
2014 & 1 & 5 \\
2015 & 1 & 5 \\
\hline
\end{tabular}

Table 2. Epidemiological, clinical and biological characteristics of cases of liver abscess, hospitalized at Fann's infectious diseases department in Dakar from 2008 to 2015.

\begin{tabular}{|c|c|c|}
\hline Characteristics & Number & Percentage (\%) \\
\hline \multicolumn{3}{|l|}{ Sex } \\
\hline Masculin & 18 & 56 \\
\hline Féminin & 2 & 44 \\
\hline \multicolumn{3}{|l|}{ Age group } \\
\hline $15-29$ years & 1 & 5 \\
\hline 30 - 44 years & 12 & 60 \\
\hline 45 - 59 years & 4 & 20 \\
\hline$>59$ years & 3 & 15 \\
\hline \multicolumn{3}{|l|}{ Time of hospitalization(days) } \\
\hline $1-20$ & 10 & 50 \\
\hline $21-40$ & 5 & 25 \\
\hline $41-60$ & 1 & 5 \\
\hline$>60$ & 4 & 20 \\
\hline \multicolumn{3}{|l|}{ Clinical signs } \\
\hline Abdominal pain & 20 & 100 \\
\hline Hepatomegaly & 16 & 80 \\
\hline Fever & 15 & 75 \\
\hline Thrill & 11 & 55 \\
\hline Pleural effusion & 10 & 50 \\
\hline Altered general state & 7 & 35 \\
\hline Jaundice & 5 & 25 \\
\hline Cough & 4 & 20 \\
\hline Pulmonary condensation syndrome & 3 & 15 \\
\hline Vomiting & 3 & 15 \\
\hline \multicolumn{3}{|l|}{ Leukocytosis $\left(\mathrm{mm}^{3}\right)$} \\
\hline$<12,000$ & 6 & 30 \\
\hline $12,000-20,000$ & 5 & 25 \\
\hline$>20,000$ & 8 & 40 \\
\hline Not realized & 1 & 5 \\
\hline \multicolumn{3}{|l|}{ Amoebic serology $(n=17)$} \\
\hline Positive & 12 & 71 \\
\hline Negative & 5 & 29 \\
\hline
\end{tabular}




\subsection{Therapeutic and Evolutionary Aspects}

Treatment was exclusively medical in 11 patients (55\%). This medical treatment was associated with surgical drainage in three patients (15\%) and Ultrasound guided aspirations in 6 patients (30\%). Medical treatment with metronidazole-ceftriaxone was the most commonly used (eight cases), followed by metronidazole-ceftriaxone-gentamicin (4 cases) and metronidazole-ampicillin-gen-tamicin ( 3 cases). The average hospital stay was 16 days with extremes of 3 days and 47 days. The outcome was favorable in 17 patients, ( $85 \%$ of cases). Complications were noted, such as a pleural rupture in one patient, another patient was transferred to a gastroenterology department, and there was one death for which the cause was not determined. The reactive or purulent nature of the pleural effusions could not be determined because the results of the punctures were unavailable.

\section{Discussion}

From 2008 to 2015, 20 cases of liver abscess were recorded at the Infectious and Tropical Diseases Clinic in Fann Teaching Hospital in Dakar, Senegal. Despite the fact that Dakar's population has grown, we observe a decrease of cases over the year's .Indeed, we recorded 17 cases of liver abscess between 2008 and 2011, and from 2012 to 2015, only three cases were noted. This decline in incidence may be due to improved standards of individual and collective hygiene, the proliferation of public health facilities and the advent of imidazole derivatives, their popularizations and their easy prescription for any dysenteric syndrome. Of these cases, 12 were confirmed amoebic liver abscesses, and in 5 patients the diagnosis of pyogenic abscess was retained. Amoebic liver abscesses are predominant in the various series reported in Africa in adults [9]. This predominance of cases of amoebic liver abscess can be explained by the high prevalence of intestinal amoebiasis in our regions, which represent the main complication [10].

The average age of 43 years of our patients was comparable to that reported by other authors [11] [12]. In our study, the male sex was predominant, and this finding corroborates data in literature for both amoebic abscess and pyogenic abscess [1] [12] [13] [14]. A history of dysentery was found in five patients, i.e. $25 \%$ of our patients, which is consistent with the results of Sankale [15] and Laverdant [16] who reported it in $30 \%$ and $20.3 \%$ of cases respectively. The existence of a history of dysentery or diarrhea should not be excluded insofar as there is no amoebiasis of the liver without colonic amoebiasis. The existence of a lag phase between the two conditions may result in an oversight. Indeed, alcohol intoxication which was noted in 7 patients is a promoting factor of liver abscesses.

The average waiting-period of 32 days before consultation in our study is greater than those reported by Service [2] and Traoré [3], which were 14.2 days and 21 days, respectively.

In a study conducted in France, this period was shorter [11]. In Africa, first 
recourse to traditional healers and self-medication are the main causes of the long delay between the presumed onset of clinical signs and hospitalization. Clinical medicine as classically defined is not always constant. Abdominal pain remains the most frequently encountered sign, although the seat is often atypical, as it was our case. It was reported by all patients in our series and remains the main symptom. This is consistent with the results of other studies [4] [17]. The detection of hepatomegaly is typical but inconstant and was reported in $80 \%$ of our patients. This frequency varies according to the studies [4] [17]. Its detection is difficult because of the pain; therefore, its actual rate may be underestimated. Other signs are considerable, such as pleural effusions which were found in half of our patients. It can be either reactional or linked to a complication.

The leukocytosis is valuable for orientation but has poor specificity because it does not differentiate etiologically. It was greater than $12,000 \mathrm{~Gb} / \mathrm{mm}^{3}$ in 13 patients. This leukocytosis was noted in $92 \%$ of Laverdant patients [16] and in $65 \%$ of Djossou patients [11].

Amoebic serology, although it is not routinely performed due to its financial inaccessibility and unavailability in public hospitals, was performed in most of our patients (17 cases or $85 \%$ ) at the Pasteur Institute of Dakar. It was positive in $12 / 17$ patients i.e. $71 \%$, which is similar to the results of Djossou [11] where the serology was positive in the same proportions. The detection of serum antibodies confirms amoebic origins. Moreover, the diagnosis of pyogenic abscess was more difficult in our context, based on indirect paraclinical arguments such as a negative amoebic serology and sometimes the appearance of the purulent fluid if a puncture was performed. Detecting the germ using an echo-guided puncture of the abscess remains the determining factor [12]. However, the puncture is not routinely performed, but remains important especially for therapeutic purposes in current practice. Even when it is done, it does not always find the germs in question, but it remains useful in identifying the germ. In Ba's series, the macroscopic appearance of pus was clearly purulent in 12 cases, and the bacteriological study of the puncture fluid identified a bacterium in 5 children [18]. In our series, the blood culture was sterile in all patients which was not great for remembering the etiology of a pyogenic abscess. Blood cultures should be done prior to antibiotic therapy, which is not always the case in current practice, and this reduces the chances of isolating a germ in the case of a pyogenic abscess.

In the clinical context, the ultrasound is the exam of choice in the diagnosis and monitoring of liver abscesses due to its easy application, effectiveness and affordable cost [9] [14] [19]. It was performed in all our patients upon admission or during hospitalization, and its sensitivity was $100 \%$. It specified the number, the seat, and the size of the hepatic collections. Thus, we found that in $90 \%$ of cases the abscess was unique. Varying percentages have been reported ranging from $65 \%$ to $77 \%$ [17] [20] [21]. The right lobe remains the preferred but not exclusive location of liver abscesses [9] [12] [22], which is consistent with our findings where abscesses were present in the right lobe in 95\%. The larger volume of the right lobe, the relative prominence of its vascularization, and mis- 
matching in the vein carry flows from the superior mesenteric vein and splenic vein, with one flowing electively to the right lobe and the other to the left lobe, are the reasons for this preferential location [19]. The size of the abscess is highly variable and can range from a few millimeters in diameter, to up to $20 \mathrm{~cm}$ or more [22]. The size of the abscess was greater than $10 \mathrm{~cm}$ in 7 patients. Indeed, the size of abscesses could be explained by the delay in consultation, and therefore the care that the patients received. In our series, only 4 patients underwent abdominal CT scans.

Therapeutically, medical treatment was exclusive in 11 patients i.e. $55 \%$ of cases, associated with ultrasound guided aspirations in $30 \%$ of cases, and with surgical drainage in $15 \%$ of cases. Medical treatment is recommended most often for small abscesses [5] [9]. Metronidazole was the only imidazole used in our study, as in most studies [5] [14] [18], to target amoebic and anaerobic etiology. Nevertheless, it was combined with Betalactamine antibiotic therapy, which in 13 cases was ceftriaxone. This therapeutic approach was performed in the majority of series on liver abscess due to the difficulty of confirmation without completing certain paraclinical exams. The ultrasound guided aspirations is a very commonly-used therapeutic method today [19]. The size of the abscesses (abscess $\geq 10 \mathrm{~cm}$ in diameter), their location in the left lobe, and the persistence of pain are indications of this technique [23]. In our study it was rather on the basis of clinical criteria including the persistence or aggravation of fever and/or hepatitis 48 to 72 hours after the start of medical treatment, that we performed this paracentesis in 6 patients. Some authors such as Nguema [13] believe that paracentesis reduce the length of hospital stays. On the other hand, according to Arm [24] the paracentesis has no significant influence on the duration of the evolution of the illness.

Surgical drainage is currently the last resort in the treatment of abscesses of the liver [19] and is most often reserved for complications, namely: peritoneal, pleural, pericardial rupture or fistulation of the abscess in a hollow viscus, or on the skin. Surgical drainage was necessary in 3 patients of our series, following a persistence of abscess to medical treatment in 2 cases and a pleural rupture in one patient.

Overall, liver abscesses have a favorable outcome with proper treatment. One case of death was observed in our series. The cases of death described in the literature are secondary to intraperitoneal rupture of the abscess [15] [25] [26]. The favorable evolution of the abscesses of the liver undergoing treatment is clinically assessed by the disappearance of pain and fever in 48 to 72 hours. The regression of hepatomegaly occurs more gradually. C-reactive protein and changes in leukocyte count are always useful for judging short-term evolution. As for the ultrasound, it can show the persistence of the abscessed cavity for several months.

\section{Conclusion}

The overall incidence of liver abscess has declined significantly in recent years. 
Amoebic serology has contributed significantly to the diagnosis of hepatic amoebiasis, hence the need to make it accessible in public hospitals. However, the diagnostic difficulty lies in the confirmation of cases of pyogenic abscess. It is necessary to strengthen and develop other diagnostic methods for these pyogenic abscesses.

\section{References}

[1] Chiche, L., Dargere, S., Le Pennec, V., Dufay, C. and Alkofer, B. (2008) Abcès à pyogène du foie Diagnostic et prise en charge. Gastroenterologie Clinique Et Biologique, 32, 1077-1091. https://doi.org/10.1016/j.gcb.2008.09.019

[2] Service, G., Camengo Police, S.M., Mobima, T., Tekpa, G., Boua Akelelo, N.P. and Koffi, B. (2014) Les abcès amibiens du foie dans le service de gastroentérologie à l'hôpital de L'Amitié de Bangui: Aspects épidémiologiques, diagnostiques, thérapeutiques etévolutifs. Journal Africain d Imagerie Médicale, 6, 4-9.

[3] Traoré, A., Togo, A., Kanté, L., Dembele, B.T., Diakite, I., Coulibaly, Y., et al. (2014) Abcès amibien du foie en chirurgie générale du CHU Gabriel Touré, Bamako. Mali Medical, 29, 5-9.

[4] Kodjoh, N. and Hountondji, A. (1991) Les abcès amibiens du foie à propos de 42 observations colligées dans les services médicaux du CHNU de Cotonou. Medecine d'Afrique Noire, 38, 185-190.

[5] Pelissier, R. (1990) La ponction échoguidée: Traitement moderne des abcès du foie. Annales De Radiologie, 33, 277-279.

[6] Greenstein, A.J. and Sachar, D.B. (1988) Pyogenic and Amoebic Abscess of the Liver Seminaris in Liver Disease. Liver Disease Journal, 8, 210-217.

[7] Charigneau Derodde, C. and Sylvain, C. (2004) Abcès bactériens du foie Gastroenterologie Clinique Et Biologique, 28, 470-476. https://doi.org/10.1016/S0399-8320(04)94961-5

[8] Lee, K.T., Sheen, P.C., Chem, J.S. and Ker, C.G. (1991) Pyogenic Liver Abscess: Multivariate Analysis of Risk Factors. World Journal of Surgery, 15, 372-377. https://doi.org/10.1007/BF01658732

[9] Dieng, M., Diop, B., Konate, I., Ka, O., Dia, A. and Toure, C.T. (2007) Traitement des abcès du foie: L'expérience d'un service de chirurgie générale. Medecine d Afrique Noire, 54, 513-519.

[10] Nozais, J.P., Datry, A. and Danis, M. (1996) Traité de parasitologie. Editions Pradel, Paris, 249-251.

[11] Djossou, F., Malvy, D., Tamboura, M., Beylot, J., Lamouliatte, H., Longy-Boursier, M., et al. (2003) Abcès amibien du foie. Analyse de 20 observations et proposition d'un algorithme thérapeutique. La Revue de Médecine Interne, 24, 97-106. https://doi.org/10.1016/S0248-8663(02)00015-2

[12] Ibara, J.R., Ollandzobo Ikobo, L.C., Atipo Ibara, B.I. and Itoua Ngaporo, A. (2000) Abcès du foie a germes pyogènes aspects cliniques, morphologiques et étiologiques à propos de 38 cas. Medecine d'Afrique Noire, 47, 92-96.

[13] Nguema-mve, R. and Graesslin, O. (1997) Traitement des abcès amibiens du foie par le drainage percutané. Medecine d'Afrique Noire, 44, 36-39.

[14] Lebeau, R., Diané, B., Yénon, S., Koffi, E., Kassi, B.A. and Kouassi, J.C. (2014) Abcès amibien du foie au CHU de Bouaké: Étude diagnostique et thérapeutique à propos de 46 cas. Mali Medical, 21, 10-14. 
[15] Sankale, M., Diop, B. and Diouf, S. (1970) Réflexions sur l'amibiase hépatique à Dakar. A propos de 223 cas observés en 10 ans. Medecine d'Afrique Noire, 17, 467-477.

[16] Laverdant, C., Denee, J.M., Roue, R., et al. (1984) L’amibiase hépatique: étude de 152 observations. Gastroentérologie Clinique et Biologique, 8, 634-844.

[17] Oudou, N., Elie, C., Ndjitoyap, N., Vincent, N. and Charlotte, N. (1999) Abcès amibien du foie à Yaoundé. Cahier Santé, 9, 119-122.

[18] Ba, I., Sagna, A., Thiongane, A., et al. (2015) Abcès du foie chez l'enfant au Sénégal. Revue Cames santé, 23, 17-22.

[19] Molinie, C. and Mennelier, D. (1997) Amibiase hépatique. Encyclopédie Médico-Chirurgicale, 7-027-A-10, 10.

[20] Weinke, T., Grobusch, M.P. and Güthoft, W. (2002) Amoebic Liver Abscess-Rare Need for Percutaneous Treatment Modalities. European Journal of Medical Research, 7, 25-29.

[21] Lodhi, S., Sarwari, A.R., Muzammil, M., Salam, A. and Smego, R.A. (2004) Features Distinguishing Amoebic from Pyogenic Liver Abscess: A Review of 577 Adult Cases. Tropical Medicine and International Health, 9, 718-723. https://doi.org/10.1111/j.1365-3156.2004.01246.x

[22] Halim, A., Bassène, M.L., Diallo, S., et al. (2016) Aspects actuels de l'amibiase hépatique à Dakar. A propos de 48 observations. Journal Africain d'H_pato-Gastroent rologie, 10, 170-175.

[23] Van Sonnenberg, E., Mueller, P.R., Schiffman, H.R., et al. (1985) Intrahepatic Amebic Abscesses: Indications for and Results of Percutaneous Catheter Drainage. Radiology, 156, 631-635. https://doi.org/10.1148/radiology.156.3.4023220

[24] Le Bras, Y., Gervez, F., Abraham, E., Toussaint, T. and Verhaegen, F. (1991) Intérêt de la ponction évacuatrice échoguidée dans le traitement des abcès amibiens du foie. Journal de Radiologie, 72, 43-47.

[25] Chuah, S.K., Chang-Chien, C.S., et al. (1992) The Prognostic Factors of Severe Amebic Liver Abscess: A Retrospective Study of 125 Cases. The American Journal of Tropical Medicine and Hygiene, 46, 398-402. https://doi.org/10.4269/ajtmh.1992.46.398

[26] Lee, C.K., Yamazaki, O., Hamba, H., et al. (1996) Analysis of 69 Patients with Amebic Liver Abscess. Journal of Gastroenterology, 31, 40-45. https://doi.org/10.1007/BF01211185 